\title{
Degree of high phenotypic plasticity in wild populations of Daphnia in early spring
}

\author{
Mariko NAGANO, Hideyuki DOI \\ Graduate School of Simulation Studies, University of Hyogo, 7-1-28 Minatojima-minamimachi, Chuo-ku, Kobe, 650-0047, Japan \\ *Corresponding author: naganoma@hotmail.co.jp
}

\begin{abstract}
Inducible defenses have been empirically known as defensive phenotypes that are triggered by predator kairomones. We hypothesized that morphological defense of wild Daphnia varies not only with predator density, but also with the predator regime in the field. We observed how the morphological defenses of two Daphnia species (D. ambigua and D. pulex) changed according to the population density in the water column at daytime of predatory insect larvae Chaoborus flavicans in Lake Fukami-ike, Japan, from February to July. In both Daphnia species, the inducible defense morphology was highly expressed in March and April. Its degree of expression decreased, and did not change with increases in predator density from May to July. These seasons are generally considered as when the number of the larvae and fish increases, and predation becomes more active due to their growth and breeding. We suggest that the degree of inducible defense of Daphnia is higher at the end of the overwintering season, when Chaoborus larvae began to inhabit the water column during the daytime and is constant in other seasons regardless of predators' regime changes. Field observation of wild populations is important for understanding the seasonal changes in the morphology, and to provide more realistic explanations of phenomena in inducible defense.
\end{abstract}

Key words: Inducible defense; morphological plasticity; phenotypic plasticity; predator-prey interaction; principal component analysis.

Received: October 2017. Accepted: February 2018.

\section{INTRODUCTION}

Phenotypic plasticity is the ability of an organism to change its phenotype in response to heterogeneous environments (DeWitt and Scheiner, 2004). The ability of freshwater organisms to bring about adaptations in reaction to environmental shifts under several ecological contexts has been shown in laboratory experiments (Relyea, 2002; Kopp and Tollrian, 2003; Decaestecker et al., 2002). The organisms using experiment and breeding environments of the laboratory used are relatively simple and unrealistic, and are different from those found in natural environments. In order to understand this ability, experiments with sufficient field observations and controls are necessary. However, research in this field is dominated by simplified laboratory studies. In situations where environmental complexity is reduced and relatively predictable, we considered that it may be worthwhile to measure the phenotypic plasticity of wild populations of plankton.

The genus Daphnia (Cladocera) occurs in variety of freshwater habitats and has been described as exhibiting cyclic or seasonal changes in morphology (cyclomorphosis) since the 1900s (Wesenburg-Lund, 1926; Havel, 1985). The cyclomorphosis of Daphnia is interpreted as predator-induced plasticity, i.e., an inducible defense (Tollrian and Harvell, 1999). Daphnia seasonally changes its morphology in response to the presence of fish and invertebrate predators (Dodson, 1989). Daphnia develops defensive traits only when it detects predators or chemical compounds, i.e., kairomones, released by predators (Harvell, 1990; Lass and Spaak, 2003). Daphnia has been shown to exhibit inducible defenses in numerous experimental studies by making changes in several morphological features: total body size, head spine (i.e., helmet) size, and tail spine length can change, and neckteeth can be developed (Hebert and Grewe, 1985; Dodson, 1989; Laforsch and Tollrian, 2004). Several morphological defenses occur simultaneously (Boersma et al., 1998; Boeing et al., 2006), and have been revealed using multi variable analysis to vary within species (Dennis et al., 2010). Although multivariate analysis is useful tool for analysis of complex morphological defenses, few recent studies have assessed how morphological defenses vary with the seasons in wild Daphnia population (except of Pijanowska, 1990; Sell, 2000).

The level of inducible defense varies in relation to predator characteristics, such as species, age-structure, density, and behavior (Lass and Spaak, 2003). In a lake ecosystem, the larvae of invertebrate insect Chaoborus are a major predator of Daphnia. The feeding habits of larval Chaoborus change by age: only older instars of larvae can eat Daphnia, depending on their gape size (Swift, 1992). Typical the yearly cycle of Chaoborus 
larvae in temperate lakes is recognized due to the high density of all instars in summer. Before summer, Chaoborus larvae are observed to be present only as fourth instar larvae, since they had remained in the diapause stage in the sediment over the winter (Stahl, 1966; Xie et al., 1998; Voss and Mumm, 1999). In early summer, the year's first generation emerges. The larvae that coexist with fish reside deeper in the water column or sediments during the daytime and migrate to upper layer at night, i.e., diel vertical migration (DVM, Teraguchi and Northcote, 1966; Dawidowicz et al., 1990; Tjossem, 1990). The migration amplitudes of the larvae vary by season; large migration amplitude is observed in summer while short or no migration occurs in winter and at low temperatures (Goldspink and Scott, 1971; Nagano et al., 2015). Given the impact of Chaoborus larvae on Daphnia, the larvae change distribution areas from sediment to water column in the daytime with simple age structure before summer. Although fishes are a predominant predator of Daphnia, fishes inhabited the lake throughout year, and rapidly increase their populations from spring to summer. Therefore, we considered that wild Daphnia from winter to early spring would show a high degree of inducible defense in response to the overwintering larvae altering distribution area from sediment to water column in daytime.

Here, we report how the inducible defenses of two Daphnia species in a lake vary seasonally with changes in the predatory Chaoborus population. We focused on two Daphnia species, D. ambigua, which has a smaller body size, and D. pulex, which has a larger body size, in Lake Fukami-ike, Japan from February to July 2004. During this observation season, the larvae inhabiting the lake were present only as fourth instar of overwintering individuals, but the habitat of the larvae gradually changed from sediments to the water column in early summer. A multivariate analysis was performed on all morphological values of inducible defense of an individual on each observed day, because multiple morphological changes of Daphnia can occur simultaneously in the presence of Chaoborus larvae. We predicted that the degree of inducible defense of Daphnia would be high when the larvae begin to emerge from sediment to the water column at daytime.

\section{METHODS}

\section{Field observations}

We sampled two Daphnia populations and Chaoborus flavicans from Lake Fukami-ike, Nagano Prefecture, Japan $\left(35^{\circ} 32^{\prime} \mathrm{N}, 137^{\circ} 81^{\prime} \mathrm{E}\right.$; maximum water depth is $7.75 \mathrm{~m}$ ), eight times from February to July, 2004. The lake is a small monomictic eutrophic lake (Nakagawa et al., 2012; Suda et al., 2016). The circulation and stagnation periods were from November to March and April to October, respectively. Two Daphnia species (D. ambigua and D. pulex), C. flavicans (Nagano et al., 2015), and planktivorous fish (bluegill sunfish Lepomis macrochirus and largemouth bass Micropterus salmoides; Kawanobe and Hosoe, 2010) inhabited the lake. Chaoborus larvae and daphnids were captured on the same observation date by vertically towing three times with a plankton net (NXX7, $930 \mathrm{~cm}$ ) above $7.5-\mathrm{m}$ depth, with sampling carried out at approximately 10:00 hrs. Samples were preserved in $10 \%$ formalin in the field, and larvae were counted and daphnids measured in the laboratory.

\section{Morphological measurements for Daphnia species}

We measured several body parts for the two Daphnia species from at least 10 individuals at each sampling date $(\mathrm{n}=330$ in total). Body length $(\mu \mathrm{m})$, head length $(\mu \mathrm{m})$, and tail length $(\mu \mathrm{m})$ (Fig. 1), and the presence or absence of head spines of Daphnia were measured using a $400 \times$ microscope.

\section{Quantification and analysis of phenotypic plasticity}

We used a principal component analysis (PCA) to compare the morphological variability of daphnids for six traits: body size, tail and head length, relative spine length (head length/body length, RHL relative head length; tail length/body length, RTL, relative tail length), and morphological type (type 1, Daphnia with tail spine; type 2, Daphnia without any spine; and type 3, Daphnia with tail spine and head spine (D. ambigua only), or tail spine and neckteeth (D. pulex only)). These were converted to $\mathrm{Z}$ distributions prior to analysis (mean, 0; standard deviation, 1).

The degree of inducible defense present at each sampling date was calculated based on the difference

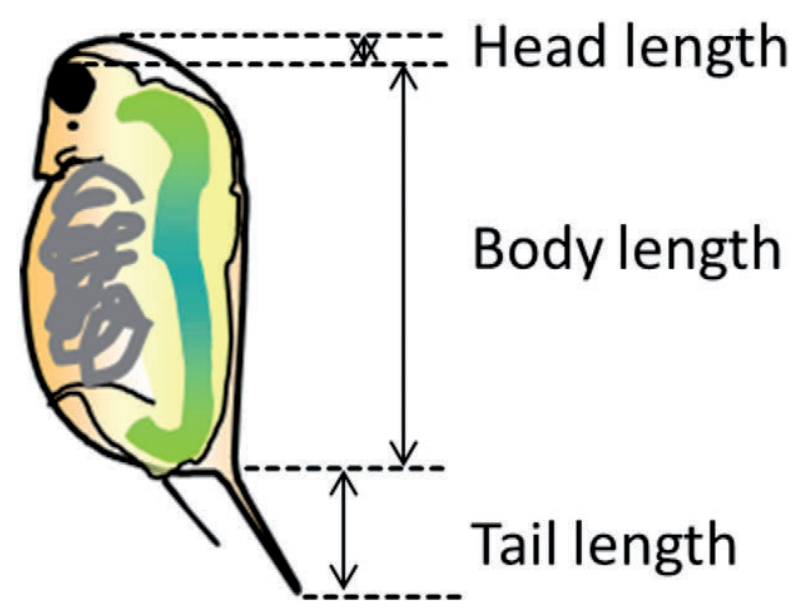

Fig. 1. Standard measurements of Daphnia individuals. 
between the February average and measurements from a Daphnia for each month sampled. In the field, morphological changes in Daphnia species are caused not only by predation, but also by environmental stresses such as food quality (Whittington and Walsh, 2015), water temperature (Miehles, 2013), and light intensity (Tollrian and Heibl, 2004; Oexle et al., 2016). Thus, these changes are more precisely called "degree of phenotypic plasticity," but we decided to use the term "degree of inducible defense" because we were measuring defensive morphology in particular. The degree of inducible defense was quantified by Euclidean distance. The method of estimation used PC scores from the first to the third main component:

$|\overline{i-c}|=\sqrt{(P C 1 f m-P C 1 F)^{2}+(P C 2 f m-P C 2 F)^{2}+(P C 3 f m-P C 3 F)^{2}}$ where: i, individual; c, control (mean value in F); fm, focal month; F, February.

Thus, if degree of inducible defense was nearly zero, Daphnia had no changes in morphology in February. In February, the predation activities of the larvae and fishes may be low in temperate lakes, especially as the larva often inhabit the sediment. Therefore, the morphology of Daphnia shown in February was used as a reference value, i.e., control. A two-way analysis of variance (ANOVA) was performed to examine the effects of Daphnia species, observation dates, and the degree of inducible defense observed. To compare the mean degree of inducible defense among observation dates, we performed a Tukey-Kramer

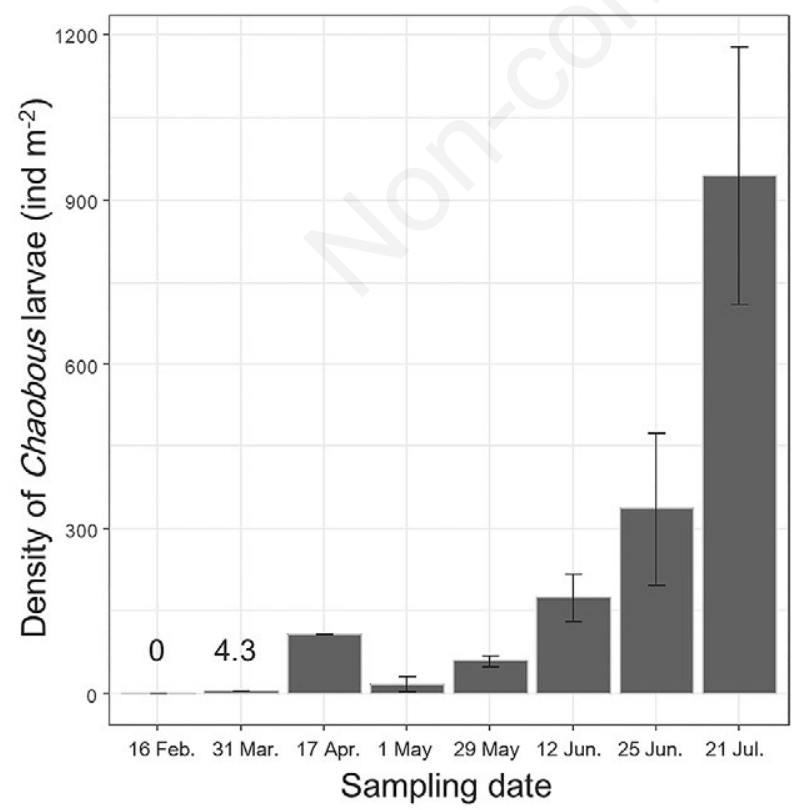

Fig. 2. Seasonal density of Chaoborus flavicans in Lake Fukami-ike, Japan. The error bar shows standard deviation (mean $\pm \mathrm{SD}$ ). The numbers for Feb. and Mar. shows the mean values. Ind, number of individuals. multiple comparison test. All analyses were conducted using R ver. 3.3.1 (R Core Team, 2016).

\section{RESULTS}

Chaoborus larvae were not observed in the water column in February (Fig. 2), probably because the larvae wintered in the diapause stage in the sediments over the winter. The larvae emerged into the water column, and were observed from March, when the larval population density remained very low. In July, the larval density was the highest observed during the season. The larval density in July was over 200 times more than that observed in March.

Daphnia ambigua was only observed in the water column from February to May 29, whereas D. pulex was noted as being present in the lake on all observation dates (Fig. 3). Examining the PCA scores obtained from analyzing six morphological features (Fig. 4), the variation in morphology explained by the first principal component (PC1) was $41.5 \%$ and was positively associated with relative tail length (RTL) and tail length. The second principle component (PC2) explained 25.2\% of the variance, and was positively associated with relative head length (RHL). The third principle component (PC3) explained $22.0 \%$ of the variance, and was negatively associated with body length. The morphology ordinate from individuals collected in

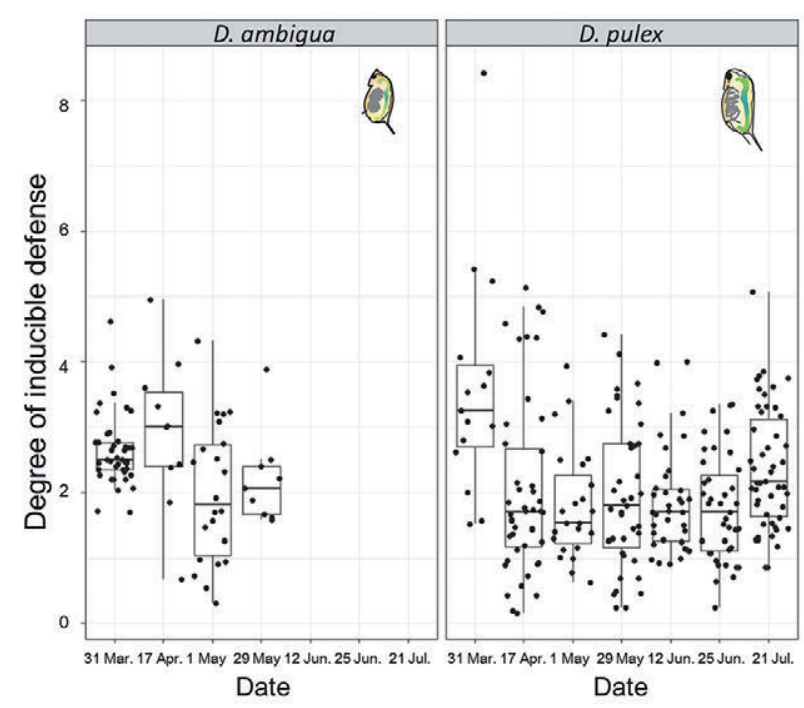

Fig. 3. Seasonal variation in degree of inducible defenses of Daphnia ambigua and D. pulex. The bar in the box, upper and lower box edges, and error bar represent the median, $\pm 25 \%$ quantile, and $1.5 \times \pm 25 \%$ quantile, respectively. Average of the PC score in February was set to zero point. Full values for all comparisons, by post-hoc testing, can be found in Tab. 1 . 
February could be assumed to be the non-defensive morphology (degree of inducible defense is zero, Fig. 3), because Chaoborus larvae were absent from the water column at daytime and migrate at night time (Nagano et al., 2015). We calculated the degree of inducible defense of the species on each sampling date (Fig. 3). Both Daphnia species exhibited their highest degree of inducible defense around March. In the case of $D$. ambigua, no significant relationships were found for the observation period (Tab. 1). In contrast, D. pulex showed a significant difference between the degree of inducible defense observed in March and that observed on other dates (Tab. 1, Tukey-Kramer multiple comparison test). A comparison of seasonal changes in the degree of inducible defense exhibited showed no differences between $D$. ambigua and D. pulex (Species $F_{1,318}=0.001$, $\mathrm{P}=0.97$; Seasons $F_{6,318}=7.52, \mathrm{P}<0.001$; Species $\times$ Seasons $F_{3,318}=5.64, \mathrm{P}<0.001$, two-way ANOVA, Fig. 2).

\section{DISCUSSION}

Despite many studies on inducible defense in laboratory experiments, research on inducible defense of wild daphnids has been limited. In this study, we found that inducible defense tends to increase during the season as

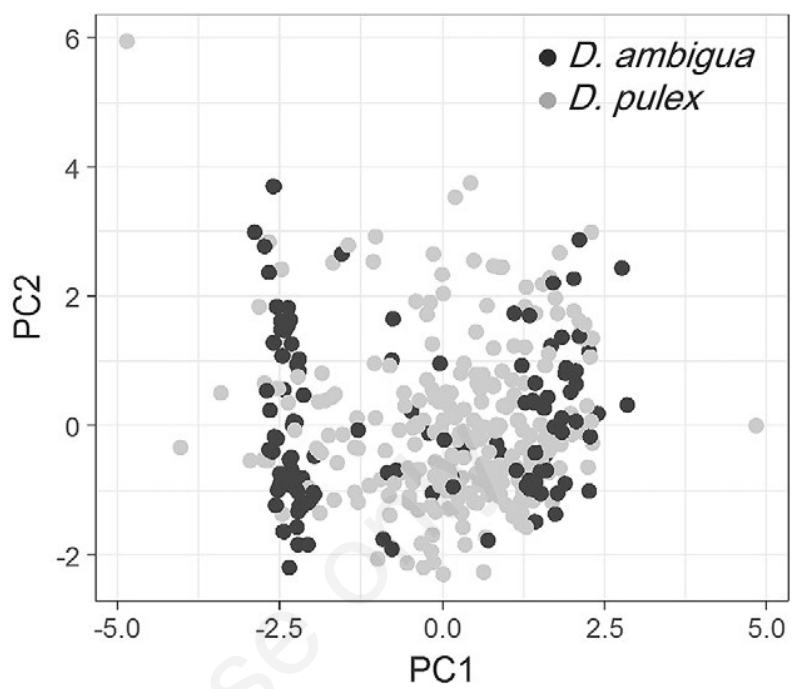

Fig. 4. Ordination of morphological values of Daphnia ambigua and $D$. pulex by principal components analysis (PCA).

Tab. 1. Results of Tukey-Kramer multiple comparison tests, comparing single pairs of the degree of inducible defense among Daphnia species and among seasons for each Daphnia species (99\% confidence interval: Conf. interval lower/upper). P-values in bold indicate significant difference $(\mathrm{P}<0.05)$.

\begin{tabular}{|c|c|c|c|c|c|c|c|c|}
\hline Treatment & Diff. & $\begin{array}{l}\text { Conf. } \\
\text { interval } \\
\text { lower }\end{array}$ & $\begin{array}{l}\text { Conf. } \\
\text { interval } \\
\text { upper }\end{array}$ & P-value & Diff. & $\begin{array}{l}\text { Conf. } \\
\text { interval } \\
\text { lower }\end{array}$ & $\begin{array}{c}\text { Conf. } \\
\text { interval } \\
\text { upper }\end{array}$ & P-value \\
\hline \multicolumn{9}{|l|}{ Among species } \\
\hline D. ambigua-D. pulex & -0.003 & -0.335 & 0.329 & 0.979 & & & & \\
\hline \multicolumn{5}{|c|}{ within D. ambigua } & \multicolumn{4}{|c|}{ within D. pulex } \\
\hline Mar.31-Apr.17 & -0.282 & -1.656 & 1.091 & 1 & 1.559 & 0.39 & 2.729 & $<0.001$ \\
\hline May.1-Apr.17 & -0.928 & -2.42 & 0.563 & 0.48 & -0.234 & -1.24 & 0.773 & 1 \\
\hline May.29-Apr.17 & -0.721 & -2.518 & 1.076 & 0.957 & -0.067 & -0.928 & 0.793 & 1 \\
\hline May.1-Mar.31 & -0.646 & -1.672 & 0.379 & 0.458 & -1.793 & -3.091 & -0.495 & $<0.001$ \\
\hline May.29-Mar.31 & -0.439 & -1.872 & 0.995 & 0.996 & -1.627 & -2.815 & -0.438 & $<0.001$ \\
\hline May.29-May.1 & 0.208 & -1.34 & 1.755 & 1 & 0.1664 & -0.862 & 1.195 & 1 \\
\hline Jul. 21-Apr. 17 & - & & & & 0.327 & -0.482 & 1.135 & 0.955 \\
\hline Jun. 12-Apr. 17 & - & & & & -0.189 & -1.075 & 0.697 & 1 \\
\hline Jun. 25-Apr. 17 & - & & & & -0.281 & -1.141 & 0.579 & 0.993 \\
\hline Jun. 12-Jul. 21 & - & & & & -0.515 & -1.378 & 0.347 & 0.55 \\
\hline Jun. 25-Jul. 21 & - & & & & -0.608 & -1.443 & 0.228 & 0.226 \\
\hline Mar. 31-Jul. 21 & - & & & & 1.233 & 0.081 & 2.384 & 0.004 \\
\hline May 1-Jul. 21 & - & & & & -0.56 & -1.545 & 0.425 & 0.633 \\
\hline May 29-Jul. 21 & - & & & & -0.394 & -1.23 & 0.442 & 0.865 \\
\hline Jun. 25-Jun. 13 & - & & & & -0.092 & -1.003 & 0.819 & 1 \\
\hline Mar. 30-Jun. 13 & - & & & & 1.748 & 0.541 & 2.955 & $<0.001$ \\
\hline May 1-Jun. 13 & - & & & & -0.045 & -1.095 & 1.005 & 1 \\
\hline May 29-Jun. 13 & - & & & & 0.121 & -0.789 & 1.032 & 1 \\
\hline Mar. 30-Jun. 25 & - & & & & 1.84 & 0.652 & 3.029 & $<0.001$ \\
\hline May 1-Jun. 25 & - & & & & 0.047 & -0.981 & 1.076 & 1 \\
\hline May 29-Jun. 25 & - & & & & 0.214 & -0.672 & 1.099 & 1 \\
\hline
\end{tabular}

Diff., difference between the average values among the compared groups. 
predatory larvae emerge from sediment. Chaoborus population in our study lake emerged into water column and gradually gained height, and probably migrated vertically, but limited in this observation periods (Nagano et al., 2015). When the lower population of larvae changed their habitat to the water column from February to March, their degree of inducible defense showed highly. After February and March, the degree of inducible defense observed decreased, and remained constant even in the presence of a high population density of Chaoborus (Figs. 2 and 4). Although the degree of inducible defense of Daphnia has been shown to be associated with predator density, i.e., high kairomone concentration, in several empirical studies (Tollrian, 1993; Dennis et al., 2010; Miyakawa et al., 2015), wild daphnia may not be as straightforward as implied by these empirical studies. In another field study, Luecke and Litt (1987) suggested that the rate of neck-teeth production of D. pulicaria did not correlate with the density of Chaoborus larvae. Another study showed that the head length of $D$. cristata and $D$. cuculata correlated with predator density, but that of $D$. hyalina did not, based on a two years of field observation (Pijanowska, 1990). These results may suggest that the degree of inducible defense was not related to predator density, but related predators moving from sediment to the water column. Daphnia fundamentally expresses different sets of inducible defense against different predators (Boersma et al., 1998; Riessen, 1999; Boeing et al. 2006). Hence, the body lengths of Daphnia become smaller to defend against fish predation, because fishes are visual predators, and prefer larger-sized prey. Additionaly, the tail length of Daphnia becomes longer to escape ingestion by fish (Dodson, 1989). On the other hand, fourth-instar Chaoborus larvae are gape-limited predators that are unable to ingest large-sized Daphnia (Swift and Fedrenko, 1975; Swift, 1992), thus, the neck spine of $D$. pulex and the head spine of D. ambigua are induced and elongated against Chaoborus larvae. Although bluegill and largemouth bass inhabited in the lake, the peak egg production of largemouth bass was before the beginning of May (Kawanobe and Hosoe, 2010). The morphological changes in Daphnia in March and April and their effects on fish predation could not be assessed, because lower water temperature may suppress the predation activity (Beitinger and Fitzpatrick, 1979). There were no coldwater fish, such as the pond smelt (Hypomesus nipponensis), in the lake (Tanaka, 1992), and February is overwintering season for fishes in the lake (Kawanobe and Hosoe, 2010). The body length of both Daphnia species in the lake increased in March. The head length of D. ambigua in April was longer than that in February. Although we investigated less type 3 morphologies (set of morphological defense against Chaoborus larvae), type 3 is exhibited in February ( $D$. ambigua) or March (D. pulex). Then, we concluded that the morphological changes observed in early spring tended to be more dependent on Chaoborus predation than fish predation. After early May, there is little change in the both of degree of inducible defense and univariate analysis, except for in the tail length. During this period, the density of the both predators will gradually increase. The inducible defense in natural Daphnia is not an effect of the predator density, or may offset the plasticity for both predators. Such field observations would allow us to clarify the relationship between the degree of prey plasticity and the predation regime, such as overwintering and hatching season.

It is important to simultaneously analyze multiple phenotypes, i.e., quantitative and qualitative traits of an individual. In our study, Daphnia individuals without any spines, i.e., type 2 morphology, were observed despite the presence of Chaoborus larvae (D. ambigua shows 11.1\% on May $29^{\text {th }}$ and $D$. pulex shows $9.5 \%$ in July). This type of Daphnia individuals may depend on other traits, i.e., behavior or life history, for their defense. Alternatively, Daphnia individuals that had spines were less prevalent during our observation period but were observed at a higher density of larvae (D. ambigua shows $4.2 \%$ in May $1^{\text {st }}$ and D. pulex shows $12.7 \%$ in July). Hammill et al. (2008) scored two morphological traits of D. pulex and showed that the score increased as predator density increased. Dennis et al. (2010) quantified the levels of inducible defense of $D$. pulex using 12 iso-female lineages with 11 traits, and reported the levels converged at higher levels of predation risk, even for different populations. Daphnia is known to exhibit clonal succession in the field (Weider, 1985; Stibor and Lampert, 2000), so it is necessary to clarify the relationship between the gene analysis of clones and their traits using multivariate analysis by long-term field study and laboratory experiment in the future.

Previous studies have discussed the effectiveness of morphological changes. From a predation experiment, $D$. pulex with neck teeth reduced Chaoborus's predation on them and were more likely to survive than other Daphnia without neck teeth (Tollrian, 1993). However, Daphnia individuals developed several types of inducible defenses at the same time (Boersma et al., 1998; Boeing et al., 2006). Hence, we supposed that the adaptation of Daphnia was to incorporate the integrative phenotypic plasticity. Then, we first proposed to estimate the "degree of inducible defense" as an index of integrative phenotypic plasticity using Euclidean distance, and we observed that the degree of the natural Daphnia population changed along with Chaoborus density in early spring. We only focused on the morphological traits for the Euclidean-distance based approach, while this method can also be used for the other traits, i.e., life history (Weider and Pijanowska, 1993) and behavioral traits (Spaak and Ringelberg, 1997). Daphnia responds to 
chemical cues from predators with multiple traits simultaneously. Daphnia temporarily take refuge against Chaoborus larvae and fish in deep water columns or anoxic strata (Hanazato et al., 1989; Salonen and Lehtovaara, 1992; Spaak and Ringelberg, 1997; Vanderploeg et al., 2009; Larsson and Lampert, 2011). In fact, Daphnia in the study lake might also show this defensive behavior with diel vertical migration (DVM), since an anoxic layer was observed in this lake (Nakagawa et al., 2012; Suda et al., 2016). Chaoborus larvae also showed DVM in the lake against fish predation (Nagano et al., 2015). In future studies, it is important to integrate these multiple defensive traits into the analysis, as well as consider how Daphnia adapts to their multiple traits against predation pressures.

Even though inducible defense studies originally started with descriptive observations, in recent years most such studies have been laboratory experiments. Evidence of inducible defense observed in natural environment is, however, of increasing importance in predicting anthropogenic effects on environmental changes. For example, the response of freshwater plankton to environmental shifts has been evaluated by studies on the effects of climate change (Chevin et al., 2013; Merilä et al., 2014) and of urbanization (Alberti et al., 2017). A zooplankton species, D. retrocurva, does not produce defensive traits or show defensive behavior, due to the use of artificial lights at night (Moore et al., 2000). In experimental settings, Daphnia has generally been made accustomed to high predator density over a period (usually three generations) (Hammill et al., 2008). In contrast, Daphnia in the field do not become accustomed to an environment with a constant predator density, but one that has seasonal dynamics. We recognize these differences between natural and experimental environments and suggest that this could explain the degree of inducible defense of Daphnia in wild populations.

\section{CONCLUSIONS}

Inducible defenses in wild Daphnia shown highly in March, late winter. After March, the degree of inducible defense decreased and became stable until July, early summer. The trends were similar among two Daphnia species, D. ambigua and D. pulex. We observed that in the distribution of Chaoborus changed only from sediments to the water column in the daytime. Additionally, we considered that the predation activity of the larvae and fish were still limited. The degree of inducible defenses was increased at high predator density and/or predatory kairomone concentrations by numerous laboratory experiments. For wild Daphnia in the lake, however, the changing predator population levels after overwintering seems important for the degree of inducible defense. We emphasize that it is even now important to investigate wild individuals and to conduct surveys in the field to further our understanding of inducible defense mechanisms.

\section{ACKNOWLEDGMENTS}

We would like to express our sincere thanks to the Anan Town authorities in Shimoina-gun, Nagano Prefecture, who provided the research facilities. We thank Dr. Sugiyama, Dr. Yagi, Dr. Tanaka, and the late Isami Shimodaira, who provided field observation advice.

\section{REFERENCES}

Alberti M, Correa C, Marzluff JM, Hendry AP, Palkovacs EP, Gotanda KM, Hunt VM, Apgar TM, Zhou Y, 2017. Global urban signatures of phenotypic change in animal and plant populations. $\square$ Proc. Natl. Acad. Sci. 201606034. DOI: https://doi.org/10.1073/pnas.1606034114

Beitinger TL, Fitzpatrick LC, 1979. Physiological and ecological correlates of preferred temperature in fish. Am. Zool. 19:319-329.

Boeing WJ, Ramcharan CW, Riessen HP, 2006. Multiple predator defence strategies in Daphnia pulex and their relation to native habitat. J. Plankton Res. 28:571-584.

Boersma M, Spaak P, De Meester L, 1998. Predator-mediated plasticity in morphology, life history, and behavior of Daphnia: the uncoupling of responses. Am. Nat. 152: 237-248.

Chevin LM, Collins S, Lefèvre F, 2013. Phenotypic plasticity and evolutionary demographic responses to climate change: taking theory out to the field. Funct. Ecol. 27:966-979.

Dawidowicz P, Pijanowska J, Ciechomski K, 1990. Vertical migration of Chaoborus larvae is induced by the presence of fish. Limnol. Oceanogr. 35:1631-1637.

DeWitt TJ, Scheiner SM, 2004. Phenotypic plasticity. Functional and conceptual approaches. Oxford University Press, New York: $247 \mathrm{pp}$.

Decaestecker E, De Meester L, Ebert D, 2002. In deep trouble: habitat selection constrained by multiple enemies in zooplankton. Proc. Natl. Acad. Sci. 99:5481-5485.

Dennis SR, Carter MJ, Hentley WT, Beckerman AP, 2010. Phenotypic convergence along a gradient of predation risk. Proc. R. Soc. B. 2778:1687-1696.

Dodson SI, 1989. The ecological role of chemical stimuli for the zooplankton: predator-induced morphology in Daphnia. Oecologia 78:361-367.

Goldspink CR, Scott DBC, 1971. Vertical migration of Chaoborus flavicans in a Scottish loch. Freshwat. Biol. 1:411-421.

Hammill E, Rogers A, Beckerman AP, 2008. Cost, benefits and the evolution of inducible defenses: a case study with Daphnia pulex. J. Evol. Biol. 21:705-715.

Hanazato T, Yasuno M, Hosomi M, 1989. Significance of a low oxygen layer for a Daphnia population in Lake Yunoko, Japan. Hydrobiologia 185:19-27.

Harvell CD, 1990. The ecology and evolution of inducible defenses. Q. Rev. Biol. 65:323-340. 
Havel JE, 1985. Cyclomorphosis of Daphnia pulex spined morphs. Limnol. Oceanogr. 30:853-861.

Hebert PDN, Grewe PM, 1985. Chaoborus-induced shifts in the morphology of Daphnia ambigua. Limnol. Oceanogr. 30:1291-1297.

Kawanobe M, Hosoe A, 2010. Extermination of the alien fishes in the Fukami pond. Annual Report of Nagano prefectural fisheries experimental station 2008:15. (in Japanese)

Kopp M, Tollrian R, 2003. Reciprocal phenotypic plasticity in a predator-prey system: inducible offences against inducible defences?. Ecol. Lett. 6:742-748.

Laforsch C, Tollrian R, 2004. Inducible defenses in multipredator environments: cyclomorphosis in Daphnia cucullata. Ecology 85:2302-2311.

Larsson P, Lampert W, 2011. Experimental evidence of a low $\square$ oxygen refuge for large zooplankton. Limnol. Oceanogr. 56:1682-1688.

Lass S, Spaak P, 2003. Chemically induced anti-predator defenses in plankton: a review. Hydrobiologia 491:221-239.

Luecke C, Litt AH, 1987. Effects of predation by Chaoborus flavicans on crustacean zooplankton of Lake Lenore, Washington. Freshwat. Biol.18:185-192.

Merilä J, Hendry AP, 2014. Climate change, adaptation, and phenotypic plasticity: the problem and the evidence. Evol. Appl. 7:1-14.

Miehles ALJ, McAdam AG, Bourdeau PE, Peacor SD, 2013. Plastic response to a proxy cue of predation risk when direct cues are unreliable. Ecology 94:2237-2248.

Miyakawa H, Sugimoto N, Kohyama TI, Iguchi T, Miura T, 2015. Intra-specific variations in reaction norms of predatorinduced polyphenism in the water flea Daphnia pulex. Ecol. Res. 30:705-713.

Moore MV, Pierce SM, Walsh HM, Kvalvik SK, Lim JD, 2000. Urban light pollution alters the diel vertical migration of Daphnia. Verh. Int. Theor. Angew. Limnol. 27: 779-782.

Nagano M, Yagi A, Yoshida T, 2015. Seasonal pattern and induction cues of diel vertical migration of Chaoborus flavicans in Lake Fukami-ike, Nagano, Japan. Ecol. Res. 30:145-152.

Nakagawa M, Ueno Y, Hattori S, Umemura M, Yagi A, Takai K, Yoshida, N, 2012. Seasonal change in microbial sulfur cycling in monomictic Lake Fukami $\square$ ike, Japan. Limnol. Oceanogr. 57:974-988.

Oexle S, Jansen M, Pauwels K, Sommaruga R, De Meester L, Stoks R, 2016. Rapid evolution of antioxidant defense in a natural population of Daphnia magna. J. Evol. Biol. 29:1328-1337.

Pijanowska J, 1990. Cyclomorphosis in Daphnia: an adaptation to avoid invertebrate predation. Hydrobiologia 198:41-50.

R Core Team, 2016. R: A language and environment for statistical computing. R Foundation for Statistical Computing, Vienna.

Relyea RA, 2002. Competitor-induced plasticity in tadpoles: consequences, cues, and connections to predator induced plasticity. Ecol. Monogr. 72:523-540.

Salonen K, Lehtovaara A, 1992. Migrations of haemoglobin-rich Daphnia longispina in a small, steeply stratified, humic lake with an anoxic hypolimnion. Hydrobiologia 229:271-288.

Sell AF, 2000. Morphological defenses induced in situ by the invertebrate predator Chaoborus: comparison of responses between Daphnia pulex and D. rosea. Oecologia 125:150-160.

Stahl JB, 1966. The ecology of Chaoborus in Myers Lake, Indiana. Limnol. Oceanogr. 11:177-183.

Stibor H, Lampert W, 2000. Components of additive variance in life-history traits of Daphnia hyalina: seasonal differences in the response to predator signals. Oikos 88:129-138.

Spaak P, Ringelberg J, 1997. Differential behaviour and shifts in genotype composition during the beginning of a seasonal period of diel vertical migration. Hydrobiologia 360:177-185.

Suda H, Tanaka M, Oyagi M, Nobori M, Yagi A, 2016. Water quality and compositions of the phytoplankton and zooplankton before and after building construction in lake Fukami-ike, Japan. Int. J. GEOMATE 10:1983-1988.

Swift MC, 1992. Prey capture by the four larval instars of Chaoborus crystallinus. Limnol. Oceanogr. 37:14-24.

Swift MC, Fedorenko AY, 1975. Some aspects of prey capture by Chaoborus larvae. Limnol. Oceanogr. 20:418-425.

Tanaka M, 1992. [11-18 Fukami-ike], p. 417-421. In: [The lakes in Japan].[Book in Japanese]. University of Nagoya Press, Nagoya.

Tjossem SF, 1990. Effects of fish chemical cues on vertical migration behavior of Chaoborus. Limnol. Oceanogr. 35:1456-1468.

Tollrian R, 1993. Neckteeth formation in Daphnia pulex as an example of continuous phenotypic plasticity: morphological effects of Chaoborus kairomone concentration and their quantification. J. Plankton Res. 15:1309-1318.

Tollrian R, Harvell CD, 1999. The ecology and evolution of inducible defenses. Princeton University Press: 383 pp.

Tollrian R, Heibl C, 2004. Phenotypic plasticity in pigmentation in Daphnia induced by UV radiation and fish kairomones. Funct. Ecol. 18:497-502.

Teraguchi M, Northcote TG, 1966. Vertical distribution and migration of Chaoborus flavicans larvae in Corbett Lake, British Columbia. Limnol Oceanogr. 11:164-176.

Weider LJ, 1985. Spatial and temporal genetic heterogeneity in a natural Daphnia population. J. Plankton Res. 7:101-123.

Weider LJ, Pijanowska J, 1993. Plasticity of Daphnia life histories in response to chemical cues from predators. Oikos 67:385-392.

Wesenburg-Lund C, 1926. Contributions to the biology and morphology of the genus Daphnia with some remarks on heredity. (K.) Danske videnskabernes selskab. Biol. Skrifer. 11:89-251.

Whittington D, Walsh MR, 2015. Divergent phenotypic responses to predators and cyanobacteria in Daphnia lumholtzi. Freshwater Biol. 60:1880-1889.

Xie P, Iwakuma T, Fujii K, 1998. Studies on the biology of Chaoborus flavicans (Meigen)(Diptera: Chaoboridae) in a fish-free eutrophic pond, Japan. Hydrobiologia 368:83-90.

Vanderploeg HA, Ludsin SA, Ruberg SA, Höök TO, Pothoven SA, Brandt SB, Cavaletto JF, 2009. Hypoxia affects spatial distributions and overlap of pelagic fish, zooplankton, and phytoplankton in Lake Erie. J. Exp. Mar. Biol. Ecol. 381:S92-S107.

Voss S, Mumm H, 1999. Where to stay by night and day: Sizespecific and seasonal differences in horizontal and vertical distribution of Chaoborus flavicans larvae. Freshwater Biol. 42:201-213. 